\title{
Effect of annealing on magnetic properties and silicide formation at $\mathrm{Co} / \mathrm{Si}$ interface
}

\author{
SHIVANi AgARWAL, V GaNeSAN ${ }^{\dagger}$, A K TYAGi ${ }^{\dagger \dagger}$ and I P JAIN* \\ Centre for Non-Conventional Energy Resources, University of Rajasthan, Jaipur 302 004, India \\ ${ }^{\dagger}$ DAE-UGC Consortium for Scientific Research, Khandwa Road, Indore 452 017, India \\ ${ }^{\dagger}$ Indira Gandhi Centre for Atomic Research, Kalpakkam 603 102, India
}

\begin{abstract}
The interaction of Co $(30 \mathrm{~nm})$ thin films on Si (100) substrate in UHV using solid state mixing technique has been studied. Cobalt was deposited on silicon substrate using electron beam evaporation at a vacuum of $4 \times 10^{-8}$ Torr having a deposition rate of about $0 \cdot 1 \AA$ A/s. Reactivity at Co/Si interface is important for the understanding of silicide formation in thin film system. In the present paper, cobalt silicide films were characterized by atomic force microscopy (AFM) and secondary ion mass spectroscopy (SIMS) in terms of the surface and interface morphologies and depth profile, respectively. The roughness of the samples was found to increase up to temperature, $300^{\circ} \mathrm{C}$ and then decreased with further rise in temperature, which was due to the formation of crystalline $\mathrm{CoSi}_{2}$ phase. The effect of mixing on magnetic properties such as coercivity, remanence etc at interface has been studied using magneto optic Kerr effect (MOKE) techniques at different temperatures. The value of coercivity of pristine sample and $300^{\circ} \mathrm{C}$ annealed sample was found to be 66 Oe and $40 \mathrm{Oe}$, respectively, while at high temperature i.e. $7_{48}^{\circ} \mathrm{C}$, the hysteresis disappears which indicates the formation of $\mathrm{CoSi}_{2}$ compound.
\end{abstract}

Keywords. Interfaces; solid state mixing; metal silicide MOKE; SIMS; AFM.

\section{Introduction}

Silicides have been studied extensively during the past decade owing to their importance as contact materials in microelectronics. As the size of the device scales down to the submicron level, an improved electrical conductivity is required for contact and high temperature stability is essential for fabrication of devices. The possibility of preparing high-quality metal silicide microstructures on semiconductor substrates with high application potential has been attracting considerable scientific and technological interest all over the world (Lau et al 1978; Van Gurp et al 1978; D'Heurle and Petersson 1985; Lim et al 1987). Metal silicides find important applications in semiconductor industry as ohmic contact, Schottky barrier, gates and interconnect (Murarka 1980). Silicide involves the diffusion of either metal or silicon or both the species across the interface at elevated temperature. Of all metal silicides, $\mathrm{CoSi}_{2}$ is widely used as gates and interconnects because of its low resistance, its silicon compatible lattice structure and can be used as a conductive and magnetic material in many electronic applications. Due to high spin polarization of carriers at the Fermi level, cobalt plays an important role on the properties of the fabricated magnetic devices (Vantomme et al 1994). Cobalt silicide has greater thermal stability and uniformity over other silicides. Therefore,

*Author for correspondence (ipjain46@ sify.com) understanding of the properties of cobalt silicide at the $\mathrm{Co} / \mathrm{Si}$ interface is of technological interest. Klasges et al have shown that the integration of magnetic layers in $\mathrm{Si}$ based devices motivated $\mathrm{Fe}$ and Co growth on Si (BulleLieuwma 1993; Liu et al 1993). The Co/Si interface has received special attention because of the existence of cobalt silicides, which have a wide range of applications in microelectronic devices due to their low electrical resistivity and small lattice mismatch with silicon (Aboclfotob et al 1994). The magnetic properties of the ultra thin $\mathrm{Co} / \mathrm{Si}$ film grown at $300 \mathrm{~K}$ have been investigated by Tsay et al (1998). The aim of the present work is to produce a smooth $\mathrm{CoSi}_{2}$ thin interface having low resistivity and high conductivity using the concept of the silicide formation during annealing at different temperatures. The depth profile measurements have been carried out using secondary ion mass spectroscopy (SIMS) for all types of samples and the magnetic properties and morphology were investigated by magneto optic Kerr effect (MOKE) and atomic force microscopy (AFM), respectively.

\section{Experimental}

\subsection{Sample preparation and annealing}

The substrate was one-side mirror polished $n$-type Si (100) wafer having an area of $1 \times 1 \mathrm{~cm}^{2}$ and of thickness, $500 \mu \mathrm{m}$. The silicon (100) substrates were first chemically cleaned by a conventional procedure (TCE, acetone, 
methanol) and then dipped into a diluted HF (1:10) solution to remove impurities of any oxide layer present before loading into vacuum evaporation chamber. Pure (99.999\%) Co metal was deposited on $\mathrm{Si}$ (100) substrate using electron beam evaporation technique at IUAC, Delhi, at room temperature. The thickness of the films was kept at $30 \mathrm{~nm}$ using quartz crystal thickness monitor. Deposition was carried out under UHV conditions at a vacuum of $4 \times$ $10^{-8}$ Torr with a deposition rate of about $0 \cdot 1 \AA / \mathrm{s}$.

Cobalt disilicide, $\mathrm{CoSi}_{2}$, was formed by the solid phase reaction between cobalt and silicon in the phase sequence of $\mathrm{Co}_{2} \mathrm{Si}, \mathrm{CoSi}$, and $\mathrm{CoSi}_{2}$ using thermal annealing at temperatures, $300^{\circ} \mathrm{C}$ and $748^{\circ} \mathrm{C}$, for $1 \mathrm{~h}$ in a $3 \times 10^{-6}$ torr vacuum using facilities at IGCAR, Kalpakkam.

\subsection{Characterization}

The SIMS, CAMECA IMS 4f instrument was used to obtain the depth profiles across the interface at IGCAR, Kalpakkam. The primary $\mathrm{Cs}^{+}$ion beam with an impact energy of $5.5 \mathrm{keV}$ was used for sputtering with the beam current of $5.6 \mathrm{nA}$. The primary ion beam was rastered over an area of $150 \times 150 \mu \mathrm{m}$ and the secondary species, $\mathrm{CsCo}^{+}, \mathrm{CsSi}^{+}$and $\mathrm{CsO}^{+}$, were collected from the central region of $60 \mu \mathrm{m}$ diameter in order to keep the sputtering rate constant at $1.8 \AA / \mathrm{s}$. The depth calibration of the SIMS profiles was achieved by measuring the depth of the sputtered craters using Sloan DEKTAK instrument. The SIMS parameters remained same for all the samples annealed at $300^{\circ} \mathrm{C}$ and $748^{\circ} \mathrm{C}$.

Pristine and annealed samples at $300^{\circ} \mathrm{C}$ and $748^{\circ} \mathrm{C}$ were studied using MOKE technique at CSR Indore, to measure the magnetic hysteresis loops. The magneto-optic Kerr effect measurements at $623.8 \mathrm{~nm}$ wavelength were performed by modulating the polarization state of the incident light using a photo-elastic modulator and employing lock-in amplifier for the detection of signal. Magnetic measurements were carried out at room temperature. The highest applied magnetic field was 1500 Gauss. In the present work, the longitudinal MOKE measurements of $\mathrm{Co} / \mathrm{Si}$ system have been carried out with Stanford Research System, Model SP830, DSP lock in amplifier having 1 amp current.

Surface morphology of samples was investigated using AFM technique at CSR Indore, performed in tapping mode, using silicon tip. On each sample, several areas were analysed to ensure the reproducibility of results. From the acquired images, root mean square (RMS) roughness was calculated.

\section{Results and discussion}

\subsection{Secondary ion mass spectroscopy (SIMS)}

The SIMS depth profile measurements of Co $(30 \mathrm{~nm}) / \mathrm{Si}$ (100) system under heat treatment with increasing tempe- rature have been carried out. Figure 1 shows the depth profile of pristine $\mathrm{Co} / \mathrm{Si}$ system and the calculated value

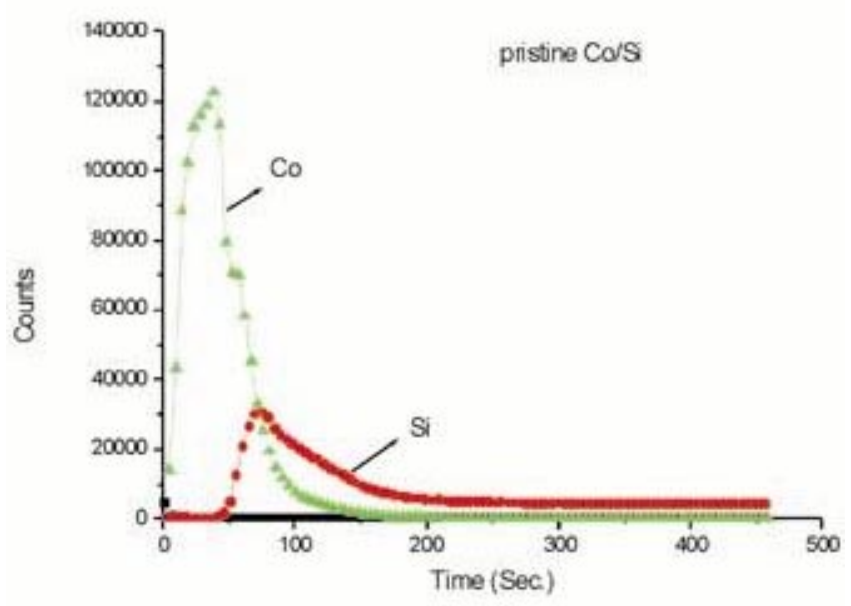

Figure 1. SIMS depth profile of pristine $\mathrm{Co} / \mathrm{Si}$.

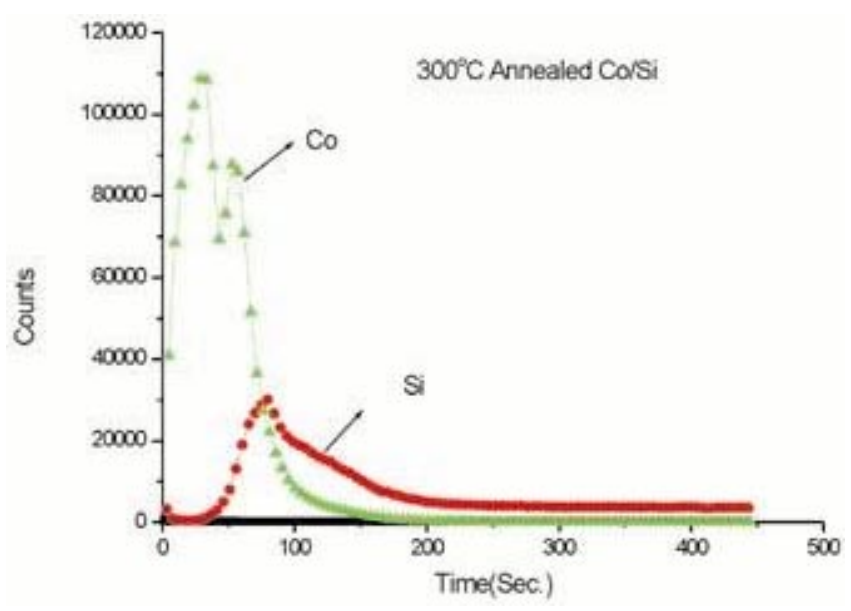

Figure 2. SIMS depth profile of $\mathrm{Co} / \mathrm{Si}$ system annealed at $300^{\circ} \mathrm{C}$.

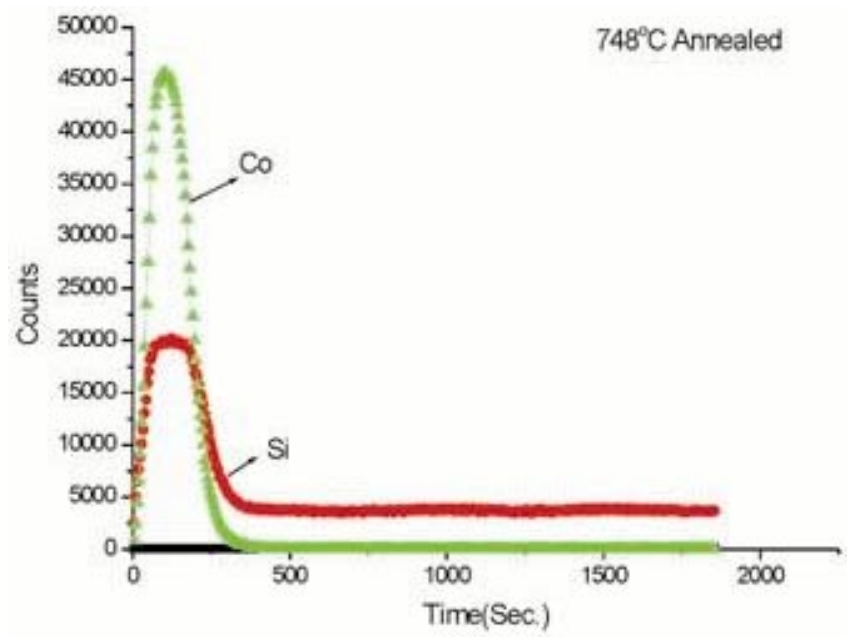

Figure 3. SIMS depth profile of $\mathrm{Co} / \mathrm{Si}$ system annealed at $748^{\circ} \mathrm{C}$. 

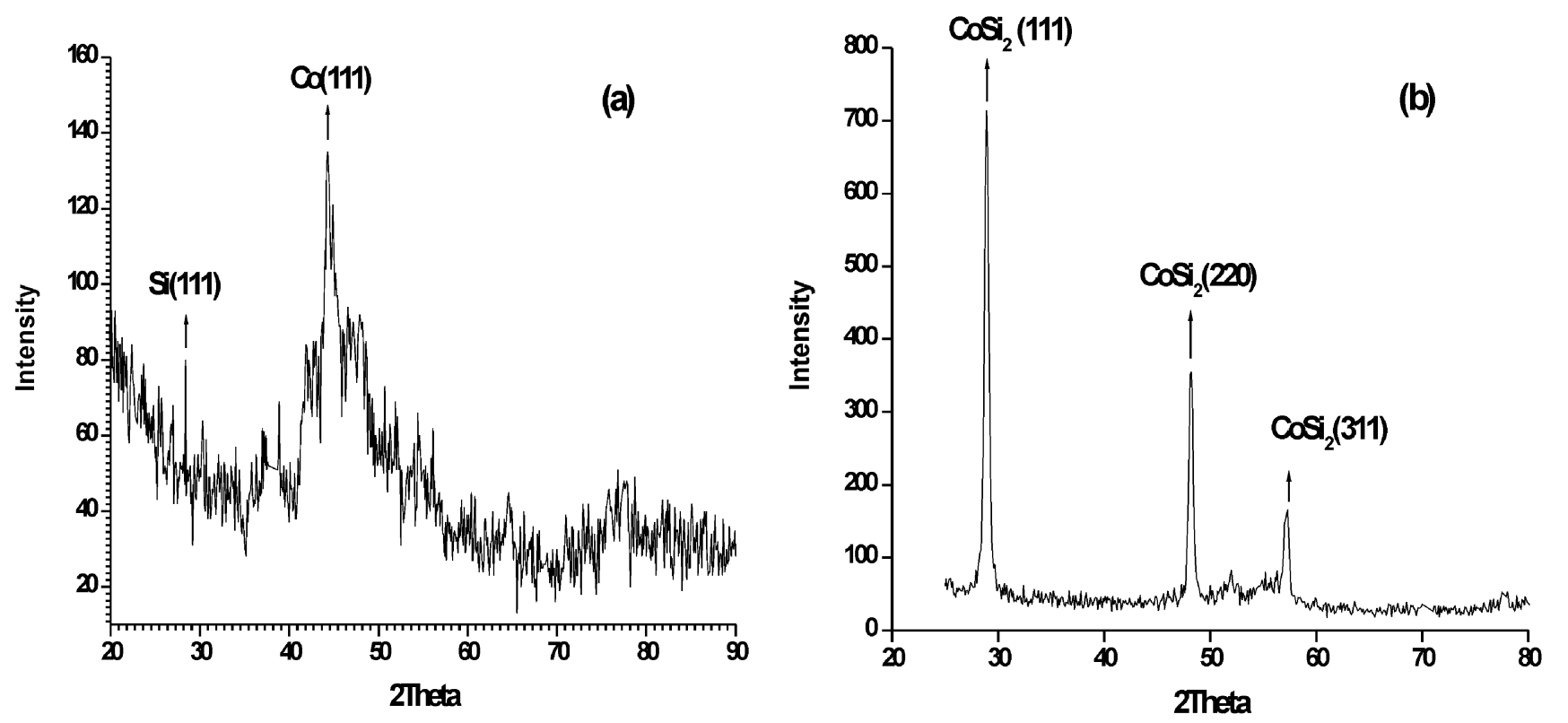

Figure 4. GIXRD of $\mathrm{Co} / \mathrm{Si}$ system: (a) pristine and (b) annealed at $748^{\circ} \mathrm{C}$.

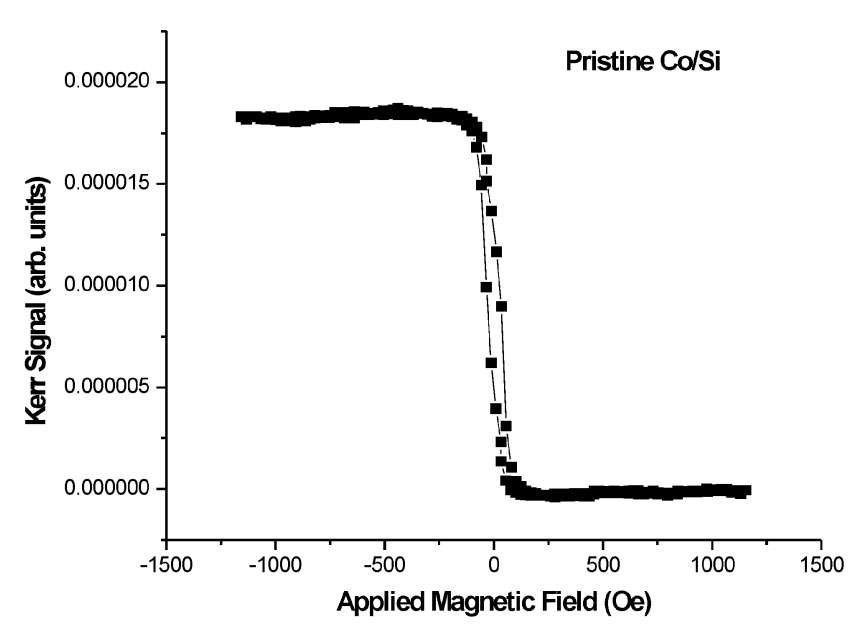

Figure 5. MOKE hysteresis loops of $\mathrm{Co} / \mathrm{Si}$ pristine system.

of intermixed region was found to be $16 \mathrm{~nm}$. As the annealing temperature of the system is increased up to $300^{\circ} \mathrm{C}$, Co partially interdiffuses in the Si resulting in the formation of silicides as shown in figure 2, which indicates mixing at the interface and the calculated value was found to be $35 \mathrm{~nm}$. The pristine and the $300^{\circ} \mathrm{C}$ annealed samples have a small splitting in Co peak at a place from where the interface has its strong part, this may be due to the fact that entire thin cobalt outer layer gets converted to the oxide form when exposed to the atmosphere during sample preparation. But we could get no splitting of Co peak due to removal of high temperature, as the annealing temperature is further increased, the calculated depth width was found to be $46.9 \mathrm{~nm}$ as shown in figure 3. SIMS

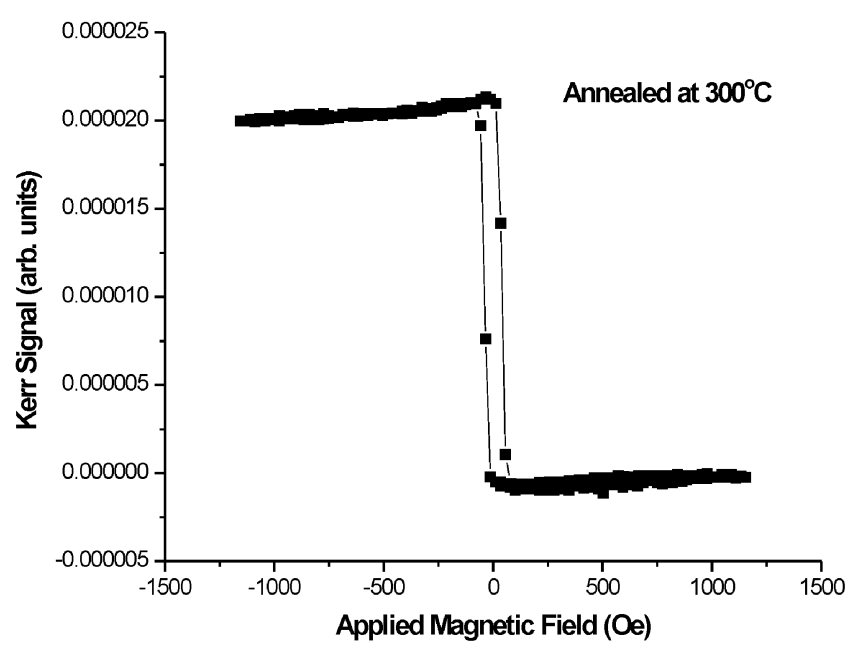

Figure 6. MOKE hysteresis loops of $\mathrm{Co} / \mathrm{Si}$ system annealed at $300^{\circ} \mathrm{C}$.

measurement is a beneficial tool that indicated that Co was well diffused in Si due to annealing. This can be calculated and it was found that as temperature increases the interface layer thickness increases causing strong mixing at the interface. To confirm the diffusion of $\mathrm{Co}$ in $\mathrm{Si}$, the GIXRD measurement has also been made on pristine and $748^{\circ} \mathrm{C}$ annealed sample and results are given in figure 4.

\subsection{Magneto optic Kerr effect (MOKE)}

Figures 5 and 6 show the data obtained from the magnetization measurements by MOKE technique for both pristine and annealed $\mathrm{Co} / \mathrm{Si}$ thin film samples, respectively. Hys- 


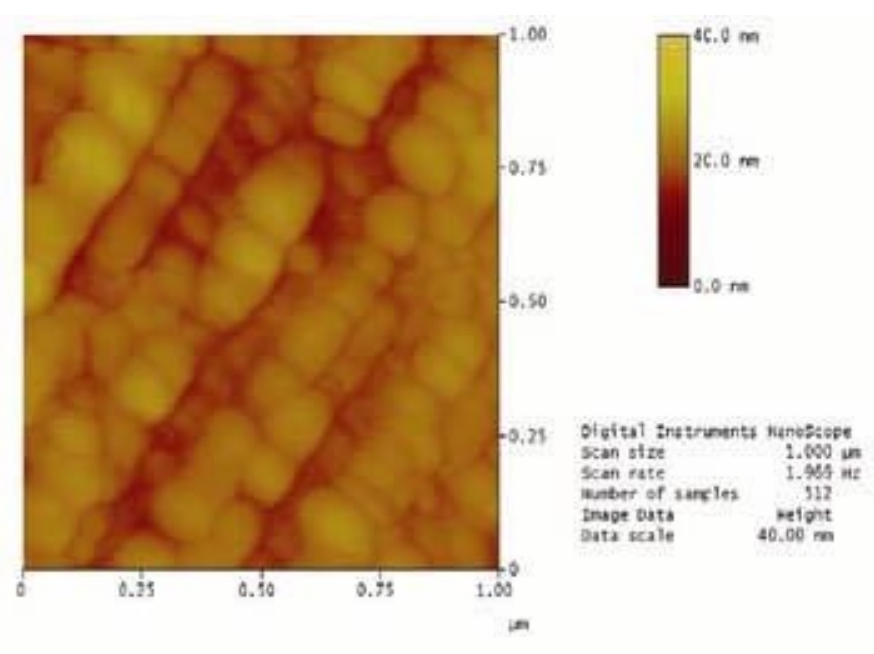

cooristr.cos

Figure 7. Morphology of $\mathrm{Co} / \mathrm{Si}$ pristine sample.
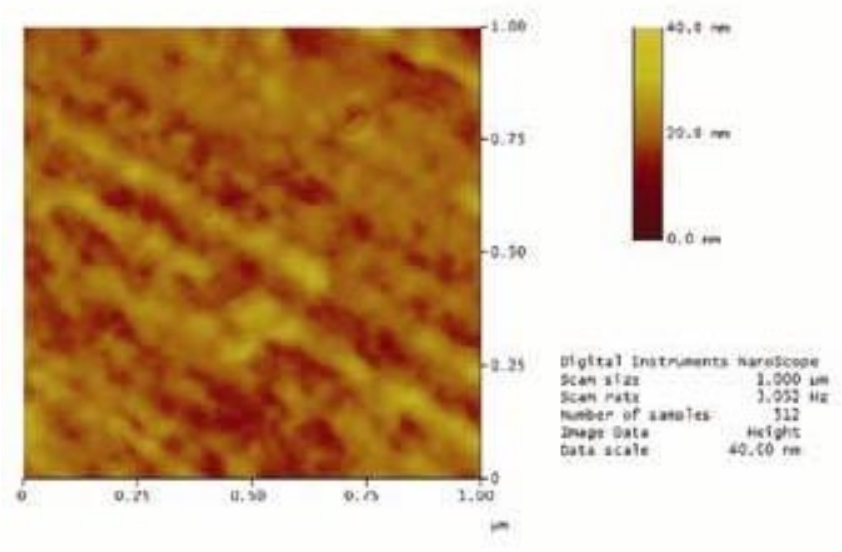

tatejoste.006

Figure 8. Morphology of $\mathrm{Co} / \mathrm{Si}$ sample annealed at $300^{\circ} \mathrm{C}$.

teresis loop measurements have been characterized by the coercivity, $H_{\mathrm{c}}$,

$$
H_{\mathrm{c}}=\left(M C_{1}+M C_{2}\right) / 2 \text {, }
$$

where $M C$ is magnetization at Curie temperature. From recorded hysteresis loops, it has been observed clearly that all the samples showed well-saturated magnetization with applied magnetic field. The coercivity value determined from MOKE hysteresis curve for the as-deposited sample has been found to be $66 \mathrm{Oe}$, for $300^{\circ} \mathrm{C}$ annealed, $40 \mathrm{Oe}$ and no hysteresis was found for annealed sample at $748^{\circ} \mathrm{C}$. At higher temperature there is complete intermixing of the $\mathrm{Co}$ and $\mathrm{Si}$ and due to this the $\mathrm{CoSi}_{2}$ phase formed after annealing at $748^{\circ} \mathrm{C}$ could be non-magnetic. This disappearance of the ferromagnetism of the film is in good agreement as viewed earlier (Wu et al 2001). These measurements show that as the temperature increases the coercivity decreases and remanence increases. The values
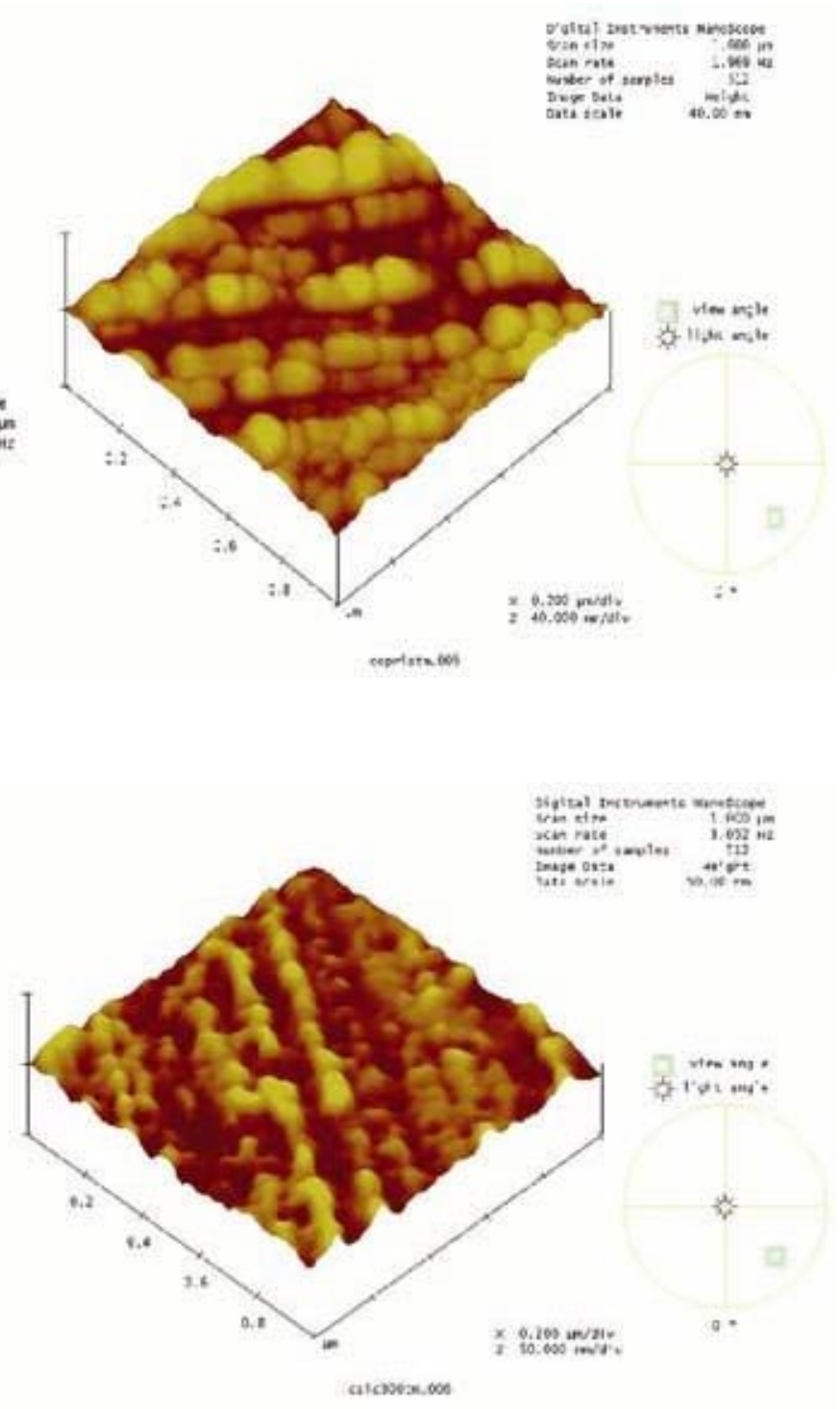

of remanence of pristine $\mathrm{Co} / \mathrm{Si}$ and annealed at $300^{\circ} \mathrm{C}$ are $0 \cdot 80$ and $0 \cdot 98$, respectively.

\subsection{AFM measurement}

Morphological changes of silicide surface during high temperature annealing have been investigated by AFM in terms of the RMS surface roughness. The scanned area of the samples is $1 \times 1 \mu \mathrm{m}^{2}$. Figure 7 indicates quite a uniform distribution and RMS roughness of $4.14 \mathrm{~nm}$ for as deposited sample. With annealing at $300^{\circ} \mathrm{C}$, the RMS roughness increases to $5 \cdot 15 \mathrm{~nm}$ as shown in figure 8 . This sharp rise in the roughness value may be due to the restructuring interface resulting from silicide reaction. Finally with annealing at $748^{\circ} \mathrm{C}$, the RMS roughness becomes $3.85 \mathrm{~nm}$ as shown in figure 9 implying the decrease in interface thickness due to crystallization, which is applicable in 


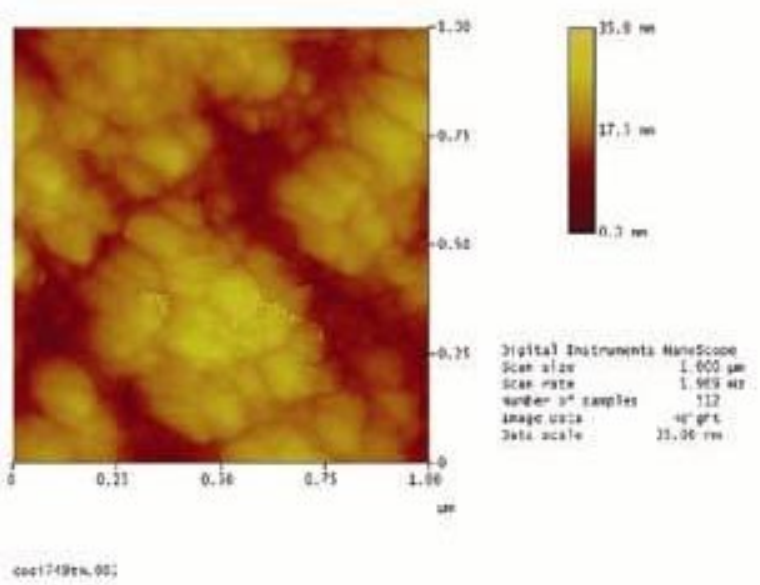

Figure 9. Morphology of $\mathrm{Co} / \mathrm{Si}$ sample annealed at $748^{\circ} \mathrm{C}$.

micro devices, because the interfacial roughness and the homogeneity of the layer is of fundamental importance. Since our sample shows smaller roughness on the top surface, further application oriented investigation is required in the field.

\section{Conclusions}

It has been observed that annealing causes a strong interface mixing at $\mathrm{Co} / \mathrm{Si}$ system. SIMS measurements show that as temperature increased the interface layer thickness also increased. It is clear from MOKE measurements that with increasing annealing temperature, the mixing rate increases and reaches a stable state at $748^{\circ} \mathrm{C}$, which is the indication of the formation of $\mathrm{CoSi}_{2}$ compound and the disappearance of magnetic properties. AFM studies show that at higher temperature, $748^{\circ} \mathrm{C}$, RMS roughness value is less than that found at $300^{\circ} \mathrm{C}$ because the interface becomes crystalline.

\section{Acknowledgements}

The authors are thankful to IUAC, New Delhi, for sample preparation. We are grateful to Dr V Reddy, CSR, Indore,

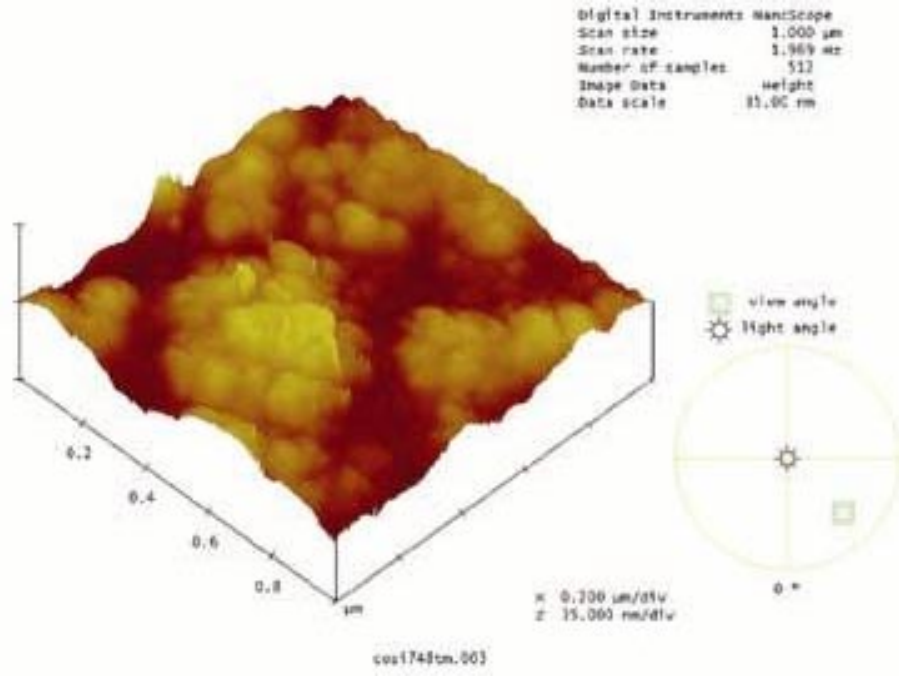

for providing MOKE facility and for useful discussion. Sincere thanks are due to IGCAR, Kalpakkam, for providing annealing facilities.

\section{References}

Aboclfotob M O, Marwick A D and Frccouf J L 1994 Phys. Rev. B49 10753

Bulle-Lieuwma C W T 1993 Appl. Surf. Sci. 681

D'Heurle F M and Petersson C S 1985 Thin Solid Films 128 283

Lau S S, Mayer J W and Tu K N 1978 J. Appl. Phys. 49 4005

Lim B S, Ma E, Nicolet M-A and Natan M 1987 J. Appl. Phys. 615027

Liu P et al 1993 J. Appl. Phys. 741700

Murarka S P 1980 J. Vac. Sci. Technol. 17775

Tsay J S, Yang C S, Yao Y D, Liou Y and Lee S F 1998 J. Appl. Phys. 375976

Vantomme A, Nicolet M-A and Theodore N David $1994 J$. Appl. Phys. 753882

Van Gurp G J, Vander Weg W F and Sigurd D 1978 J. Appl. Phys. 494011

Wu Y E, Tsay J S, Chen S C, Fu T Y and Shern C S 2001 Jpn J. Appl. Phys. 406825 